\title{
How is Information Systems Research Justified? An Analysis of Justifications Given by Authors
}

\author{
Kai Spindeldreher \\ University of Cologne \\ spindeldreher@wiso.uni-koeln.de
}

\author{
Daniel Schlagwein \\ The University of Sydney \\ schlagwein@sydney.edu.au
}

\author{
Detlef Schoder \\ University of Cologne \\ schoder@wim.uni-koeln.de
}

\begin{abstract}
This study analyses how Information Systems (IS) research is justified by authors. We assess how authors justify their research endeavors based on published IS research papers. We use justification theory [11], which along with later work, identifies seven different value systems (i.e., orders of worth) as co-existing in society, as a conceptual foundation. We qualitatively and quantitatively analyze the justifications in published IS research papers. We provide a breakdown of the justifications used in IS research. Our findings show that the importance and relevance of IS research is predominantly justified in reference to three orders of worth (market, industrial and civic values) at the neglect of the four other orders of worth (domestic, inspiration, fame, green) that equally exist in society. We provide suggestions to stimulate a broader consideration of research topics in relation to these other orders of worth and hence alternative sources of justification for authors.
\end{abstract}

\section{Introduction}

This paper does not presume the overall direction and justification of Information Systems (IS) research as correct and given, but analytically examines and critically questions this very direction.

In recent years, scholars in all management fields are challenged to justify the relevance and legitimacy of their research beyond traditional definitions of scientific rigor [32]. The call for increasing practical relevance of IS research in particular, has led to the "rigor vs. relevance" debate. The rigor vs. relevance debate in IS [e.g., 9 , 16] discusses "scientifically rigorous" versus "practically relevant" research. Several researchers have emphasized the importance of relevance of IS research and proposed suggestions and guidelines to improve the relevance of IS research. For instance, Robey and Markus [40] emphasize that relevance of IS research can be achieved by making it "consumable" for practitioners. Others suggest that relevance could be increased by grounding the selection of topics on practitioners' needs [9] and by making it accessible and suitable for applicability checks [41]. It is widely accepted today that IS research does not only need to be "rigorous" (typically understood as following accepted research methods) but also "relevant" (typically understood as having practical impact).

The idea of "relevance" of IS research appears to be inherently grounded in its market and industry needs based justification, by subscribing to monetary (market) and efficiency (industry) ends [15]. That is, research is relevant if the knowledge produced is "directed at economical practice and application in "human enterprises"' [30 p. 221]. Such studies aim for "efficiency", "effectiveness", "cost reduction" etc. [e.g., 44]. This can be an implicit and indirect aim. For example, a study may focus on the desire of online product reviewers to gain attention and reputation [43]. However, gaining attention and reputation is not considered as the causa finalis, but rather as a means towards providing managerial implications for companies (hence, the study is ultimately justified by monetary considerations). Any notion of relevance or justification outside of market effects and industrial effects are hardly considered in IS research [15].

There are some notable exceptions to this exclusive focus on market and industrial justification. For example, "green IS" has emerged as a research stream that focuses on IS as a means to improve environmental sustainability. The relevance of green IS research is justified by the wish to mitigate the effects of climate change and other environmental problems, not economic considerations [51]. This shows that a single interpretation of relevance (namely, relevance in managerial and economic value orders) should not and has not be accepted universally [15]. One could argue that relevance of research lies in pursuing general knowledge that serves long term interests of society [15], which is certainly not limited to a market and industrial view on what is valuable. For example, is art not an end in itself? 
Extensive empirical work in sociology - notably work in the domain of "justification theory" $[11,45]-$ has identified that there are actually seven co-existing coherent value systems throughout Western societies: Market, Industrial, Civic, Domestic, Inspiration, Fame, Green [11 , 45]. While prima facie observations are possible, we do not know in detail which justifications, according to which value systems, IS researchers actually use in the choosing their research subjects, framings and designs. In this paper, we assess the current state of the IS research field in terms of the justification of research. In other words, we pose and answer the question: How is research justified in the IS field?

To answer this fundamental question, we examine the justifications that researchers (explicitly or more often, implicitly) provide when describing the motivation, purpose and relevance of their research. We use justification theory (or, orders of worth framework) $[11,45]$ to map the justifications for the given research endeavor for all papers published in two leading IS journals, MIS Quarterly and Information Systems Research, from 2014 to 2017). We provide a breakdown of the justification used in IS research, and critically assess the current status and implications for future research in the IS field.

\section{Legitimacy of IS research}

Since its inception, the IS field has devoted significant effort to the question of its legitimacy and how it is to be adapted or positioned to achieve such legitimacy. The field has been engaged in "defining its domain, establishing its legitimacy, reflecting and critiquing its contributions, and tracking its progress as an academic discipline" [18 p. 361]. The underlying central question of many resulting debates has been how the IS field can establish legitimacy [26].

These legitimacy debates have often centered around different characteristics of the IS research field. As above, one such characteristic has been the rigorous application of scientific methods. Many see the rigorous application of methods to legitimize the IS research field as a science in accordance with our academic institutions [40]. A different characteristic (often perceived as a contrary or alternative characteristic to "rigor") has been the practical "relevance" of IS research [c.f. 9, $16,39,40,41]$. From this point of view, the legitimacy of IS research is based on its relevance to practitioners. A further prominent characteristic is the IS field's diversity of methods and topics [cf. 8, 9, 39]. Some researchers see diversity as a strength for the legitimacy of IS research [e.g., 39] while others rather see a threat in a "missing core" [e.g., 8]. The existence and the contribution to a specific core of knowledge, such as a theoretical core [30], core IT artefact [34] or core properties [10] has also received substantial attention.

To assess and judge the legitimacy of the IS field directly, various assessments and guidelines have been proposed. Legitimacy of the IS field can be considered as being conceptually rooted in both, the mindset of externals (cognitive legitimacy) and in the actions of insiders (behavioral legitimacy) [18]. Lyytinen and King [30] propose a model of disciplinary legitimacy grounded in three drivers: the salience of the issues studied, the production of strong results and the maintenance of plasticity (a field's ability to adapt to shifting salient issues). Agarwal and Lucas [2] propose that legitimacy and relevance should be assessed based on three aspects: (1) existence of a non-trivial aspect of the underlying theory that draws upon IT's unique nature; (2) implications for the studied phenomenon through the involvement of an IT artifact; and (3) illumination of scholarly and practitioner understanding related to IT construction, management and effects.

While the above conceptualizations and assessments of legitimacy of IS research at field are useful, we ground our assessment of legitimacy in the sociological conceptualization. In the sociological framing, legitimacy is viewed as the "appraisal of actions in terms of shared or common values in the context of the involvement of action in the social systems" [35 p. 175]. Legitimacy is grounded in the accordance of that which is to be legitimized with people's values. These values reflect the types of objects, persons or phenomena that people value and seek. Legitimacy, in this context, can be assessed by an examination of the prevalent values and norms [20].

We assess the legitimacy through an analysis of justifications across individual IS research papers. That is, we base our assessment on - and it is meant to describe an open to critical assessment - the actual justifications given in papers. We ground the position on the notion that "any effort to understand the state of the IS field has to view IS research as a series of normative choices and value judgements about the ends of research" made by the individual IS researcher [15 p. 1]. A research article can be seen as a device for communication in which researchers, inter alia, justify the legitimacy of their work towards their audience [42]. As a foundation for our analysis, we consider the statements in relation to the justification of research in IS papers. We take these statements at face value (what is actually stated in writing; ignoring the external factors that influenced the development and publication of papers such as peer review, influences of 
departments, editors etc. - we will return to this aspect in the Discussion section).

\section{Justification of IS Research}

While legitimacy, as above, refers to the "state" of legitimacy, legitimation or justification refers to the process - in our case primarily the textual/rhetorical processes - of achieving this state. That is, if authors' legitimation or justification efforts succeeds with the target audience, then the text has achieved legitimacy. For example, authors might argue in a paper that they focus on increasing organizational performance (an important goal in industrial production logic) and base their claims on an "accepted" and "appropriate" research method. If the audience (including reviewers) approve this justification, then the paper has achieved a level of legitimacy. In line with "justification theory", we use the term "justification" in the following.

Various frameworks and theories have been proposed under the umbrella of "institutional logics" [cf. 48]. These frameworks and theories seek to help us understand behavior at both individual and institutional levels. "Institutional logics" can be described as the socially constructed, historical patterns of cultural symbols and material practices, including assumptions, values and beliefs, by which individuals and organizations provide meaning to their social reality [47]. Institutional logic frameworks provide a means to analyze the behavior of individuals and organizations in social systems through institutional orders [48].

One particular version of "institutional logics", the "orders of worth" theoretical framework proposed by Boltanski and Thévenot [11] alluded to above, provides a theory of justification in societies. The theory and framework allow for an analysis of how people justify their actions [17]. The justifications of actions are grounded in seven orders of worth: market, industrial, civic, domestic, inspiration, fame and green. An order of worth represents a set of internally coherent principles and norms that refer to what people place value on [46]. People (implicitly) relate to these orders of worth when they justify their actions to maintain or obtain legitimacy [36]. People can justify their actions based on a single order of worth, or on multiple orders of worth. The orders of worth theory acknowledges that the various orders are symmetrical (i.e., no order of worth is inherently superior) [36]. In short, the orders of worth explain how we justify our views and actions to others.

There are seven different orders of worth and their sources of worth. In the market order, justification depends on profit maximization and competition. An actor in this order values people and objects according to their wealth, based on market mechanisms. In the industrial order, justification depends on productivity, efficiency and reliability. An actor in this order values people and objects that work and act efficiently and reliably. In the civic order, justification depends on collective welfare, solidarity and equality. An actor in this order values people and objects according to the benefits provided to the common good, potentially at the expense of individual benefits. In the domestic order, justification depends on hierarchy, trust, honesty and tradition. An actor in this order values people and objects that entail high levels of status and trust that are determined by an interpersonal chain of dependencies. In the inspiration order, justification depends on uniqueness, creativity, inspiration and passion. An actor in this order values intrinsically generated enjoyment, independently from external recognition or judgement. In the fame order, justification depends on reputation, fame and public opinion. An actor in this order values people and objects that provide public esteem and popularity, independently from intrinsic self-esteem. In the green order, justification depends on ecological sustainability and environmental friendliness. An actor in this order values the provision of long-term benefit to the ecological environment by people and objects. The green order of worth was not included in the original framework [11] but was added in subsequent work [45].

The comprehensive and theoretically rich framework developed by Boltanski and Thévenot [11] has been espoused by sociologists due to its ability to understand actors" "modes of justification" in a social context [19 p. 277]. IS research is a social context in which justification are used. Notably, authors justify and audiences (such as reviewers, editors, readers, grant-given boards and tenure committee) are to be convinced. In each study, every IS researcher unavoidably makes choices around desirable outcomes and impact of their research [15]. Papers comprise the justifications that the respective authors provide to justify their research to the audience [39]. Thus, we assess the legitimacy of the IS field by considering the set of individual research endeavors and their respective justifications provided by the authors in the resulting published papers.

The orders of worth framework is suited for the current study as it enables us to systematically analyze and understand (in a higher, theoretical level of abstraction) the explicitly and implicit justifications of research (given by IS research authors). The framework acknowledges the existence of multiple types of valid logics of justification. Hence, it matches with the critically-reflected acknowledgement that a single interpretation of relevance of IS research should 
not be accepted universally and multiple valid interpretations can co-exist.

\section{Research method}

To examine the justifications used by authors in the IS research field, we analyzed a corpus of recently published IS research papers. The papers were published in the journals MIS Quarterly (MISQ) and Information Systems Research (ISR). We selected these two journals because they are generally considered to be among the leading IS journals. We collected all papers from MISQ and ISR that were published in a three-year period from 2014 (January) to 2017 (June). The papers were published immediately prior to the time of our data collection (June 2017). The three-year time period of the published papers was chosen with the aim to collect a number of papers that constitute a rich and recent data set. In total, our data set included 295 papers (142 papers from MIS Quarterly, 153 papers from Information Systems Research).

Our analysis proceeded as follows. We coded each article for the justification of the given research endeavor according to the orders of worth theory. The first step was the identification of the justification in which the authors outline why their research is relevant (and for whom). As opportunities for contribution of research are developed in the introductory parts of an article [27] we focused on the introduction and the abstract for the identification of justifications. The justifications we identified were mostly provided in the form of a problem statement or relevance statement. Occasionally, when the introductory parts of an article did not include a justification, we found a justification through the given implications of the respective findings (i.e., authors outlined the benefits). We collected the justifications as quotes (sometimes more than one sentence) with which we continued to work. We then tried to locate semantic descriptors within the justifications. Semantic descriptors represent terminological markers (terms) that are linked to a specific order of worth [36]. The second column of table 1 shows a set of semantic descriptor exemplars and their corresponding order of worth based on existing lists $[11,36]$.

We then allocated the respective papers to the corresponding orders of worth. We allocated papers to multiple orders of worth if it was applicable (i.e., the article included justifications based on multiple orders of worth). We primarily allocated an article to an order of worth based on the semantic descriptors in its justification. While allocating the papers based on the semantic descriptors, we judged whether the detected semantic descriptor was used in a different context than originally described. That is, we did not base the allocation solely on the occurrence of a semantic descriptor but also on our assessment of the context of its use. We carefully avoided coding semantic descriptors that were not part of the justification for the research but that instead related to the research topic analysis. For example, the study of Shen, $\mathrm{Hu}$ and Ulmer [43] is concerned with the strategic behavior of online product reviewers seeking to gain attention and enhance reputation. While semantic descriptors would point towards the fame order (reputation and attention are an end in itself), the research is explicitly justified by its managerial implications for companies (the purpose of the study is to support firm performance) and based on the market order.

We allocated 236 papers of the 295 papers to at least one order of worth (one article can be justified through multiple orders of worth). We could not allocate the remaining 59 papers (27 MIS Quarterly, 32 Information Systems Research) because they did not allow for an allocation to any order of worth as their research justification was based on abstract and general purposes (such as widely applicable methodological or theoretical improvements). For example, the article by Hong, Chan, Thong, Chasalow and Dhillon [23] discusses the value of considering context in theory development in IS research. However, the application of this contextualized theory development was not specified (either implicitly or explicitly) in regard to a specific purpose. In fact, it could be applied to research with a variety of justifications/purposes.

\section{Findings}

Table 1 shows an overview of how many IS research papers referred to which order of worth. The first column of Table 1 shows the seven orders of worth. The second column shows exemplary semantic descriptors and sources of worth for each order of worth. The third column shows example statements in IS research that are used to justify the given research in the respective order of worth. The fourth column shows the absolute number of papers and the percentage of papers that include a justification in the given order of worth. Note that an article was allocated to multiple orders of worth if the article includes multiple justifications within different orders of worth (hence numbers add up to more than 100\% / 236 papers). The three dominant orders of worth in Information Systems research papers are: the market order $(63.1 \%$ of all papers), the industrial order $(25.0 \%)$, and the civic order (19.5\%). In contrast, very few papers include justifications within the domestic 
order $(2.1 \%)$, the inspiration order $(0.4 \%)$, the fame order $(2.5 \%)$, and the green order $(0.9 \%)$. The manifestations of the seven orders of worth in the literature are outlined below.

Table 1. Justification (orders of worth) of published IS research

\begin{tabular}{|c|c|c|c|}
\hline $\begin{array}{c}\text { Order of } \\
\text { Worth } \\
\text { (Value } \\
\text { Systems } \\
\text { Used for } \\
\text { Justification) }\end{array}$ & $\begin{array}{l}\text { Semantic } \\
\text { Descriptor } \\
\text { (Sources of } \\
\text { Value in this } \\
\text { Value System) }\end{array}$ & Example Statements in IS Research & $\begin{array}{l}\text { Number of IS } \\
\text { Research Papers } \\
\text { in Population } \\
\text { Referring to } \\
\text { Order of Worth }\end{array}$ \\
\hline Market & $\begin{array}{l}\text { Money, price, } \\
\text { cost, profit, } \\
\text { competition }\end{array}$ & $\begin{array}{l}\text { "information asymmetry between clients and vendors }[\ldots] \text { give rise to } \\
\text { opportunities for specialist third-party advisors. }[\ldots] \text { Yet, }[\ldots] \text { actual } \\
\text { use of third-party advisors is in low single digit percentages. [...] This } \\
{[\ldots] \text { motivates us to address the issue of quantifying their impact }[\ldots]} \\
\text { In particular, this paper investigates the impact of third-party advisors } \\
\text { on vendors' revenue and contract outcomes" [5 p. 637] }\end{array}$ & $149(63.1 \%)$ \\
\hline Industrial & $\begin{array}{l}\text { Efficiency, } \\
\text { reliability, } \\
\text { productivity }\end{array}$ & $\begin{array}{l}\text { "If the uncertainty cannot be resolved effectively, it can translate into } \\
\text { volatility of firm performance, namely firm risk" [ } 49 \text { p. 40] }\end{array}$ & $59(25.0 \%)$ \\
\hline Civic & $\begin{array}{l}\text { Collective } \\
\text { welfare, } \\
\text { common good, } \\
\text { solidarity, } \\
\text { equality }\end{array}$ & $\begin{array}{l}\text { "In this manuscript, we build on and extend these two traditions by } \\
\text { considering societal impacts of a new arena of digitization. [...] } \\
\text { Investigating these impacts is important because mass media coverage } \\
\text { influences legislative and policy agendas of presidents and of Congress } \\
\text { directly and indirectly" [31 p. } 304]\end{array}$ & $46(19.5 \%)$ \\
\hline Domestic & $\begin{array}{l}\text { Hierarchy, trust, } \\
\text { honesty, } \\
\text { tradition, } \\
\text { family, identity }\end{array}$ & $\begin{array}{l}\text { "This situation often engenders the risk of resettled refugees being } \\
\text { excluded from full participation in society. [...] how their use of [IT] } \\
\text { facilitates opportunities for their participation in social, cultural, } \\
\text { political, and economic life" [4 pp. } 405-406]\end{array}$ & $5(2.1 \%)$ \\
\hline Inspiration & $\begin{array}{l}\text { Inspiration, } \\
\text { creativity, } \\
\text { passion, } \\
\text { enthusiasm }\end{array}$ & $\begin{array}{l}\text { "If people experience or anticipate such opportunistic } \\
\text { free-riding behavior, this may lead to underinvestment } \\
\text { or withholding of information, thus impeding innovation } \\
\text { activities" } 6 \text { p. } 725]\end{array}$ & $1(0.4 \%)$ \\
\hline Fame & $\begin{array}{l}\text { Public image, } \\
\text { public opinion, } \\
\text { recognition }\end{array}$ & $\begin{array}{l}\text { "this topic is important because significant public opinion in society is } \\
\text { known to be influenced by user exposure to news" [ } 37 \mathrm{p} .569]\end{array}$ & $6(2.5 \%)$ \\
\hline Green & $\begin{array}{l}\text { Environmental } \\
\text { friendliness, } \\
\text { ecological } \\
\text { sustainability }\end{array}$ & $\begin{array}{l}\text { "Information Systems (IS) innovations can play a decisive role in this } \\
\text { situation by influencing participants' environmental beliefs through } \\
\text { information, by coordinating and optimizing electricity networks, and } \\
\text { by transforming the current centralized approach to electricity } \\
\text { provisioning" } 25 \text { p. } 448]\end{array}$ & $2(0.9 \%)$ \\
\hline
\end{tabular}

Papers justified in the market order usually strive for economic success through increased value and profits and decreased economic costs and prices. Such papers justify their research for example by: "help[ing] advertisers better evaluate their relative performance for different positions for various types of keywords" [1 p. 538], increasing revenue for vendors of outsourcing relationships [5], or allowing "practitioners to develop their own pricing plans and pricing metrics selection" [13 p. 596]. Justifications in the market order were often the sole justification for research. However, justifications in the market order were occasionally accompanied by justifications in other orders of worth (mainly industrial order).

Papers justified in the industrial order usually strive for efficiency and reliability of organizations and artefacts. Such papers justify their research for example by: reducing firm risk [49], providing "guidance on how strategic alignment can mediate the effectiveness of IT governance on organizational performance" [52 p. 497], or determining the benefits of health IT on the reallocation of resources and the consequences for efficiency and organizational performance [53]. Justifications in the industrial order were frequently the sole justification for research. However, they were also occasionally accompanied by justifications in other orders of worth (mainly the market order).

Papers justified in the civic order usually strive for collective benefits, equality and solidarity. Such papers justify their research for example by: providing guidance to countering negative societal effects of 
mass media [31], supporting the empowerment and self-development of marginalized communities [28], or increasing safety for students on campuses [22]. Justifications in the civic order were usually the sole justification for research. However, they were also occasionally accompanied by justifications in the market order and industrial order.

Papers justified in the domestic order usually strive to enhance trust and belongingness among people and objects. Such papers justify their research for example by: fostering the formation of a cultural identity in the light of refugee's public participation and inclusion [4], identifying community leaders and community hierarchies [24], or highlighting the relationship of IT and people's identity [12]. Justifications in the domestic order were most often accompanied by justifications in other orders of worth (especially market order and civic order).

Papers justified in the inspiration order usually strive to provide means for activities or objects that foster a person's creativity, passion and inspiration. Such papers justify their research for example by fostering innovation activities and the innovator's intrinsic enjoyment, passion and creativity [6]. Justification in the inspiration order was accompanied by justifications in the market order.

Papers justified in the fame order usually strive to provide means towards earning external recognition, public opinion and fame. Such papers justify their research for example by: highlighting the danger of manipulated news recommendation algorithms for the integrity of public opinions [37], or drawing attention to the negative consequences of involuntary exposure of personal private and sensitive information online for people's social status, public image and public attention [14]. Justifications in the fame order were most often accompanied by justifications in the civic order and market order.

Papers justified in the green order usually strive to improve ecological, environmental and long-term sustainability. Such papers justify their research for example by: highlighting the need to reduce carbon emission levels [25] or by aiming to support scientists in the area of climate change [50]. Justifications in the green order were most often accompanied by justifications in the civic order.

Some notable differences can be found in regard to justification strategies between papers that were allocated to the common orders of worth (market, industrial, civic) and papers that were allocated to the uncommon orders of worth (domestic, inspiration, fame, green). First, papers allocated to the common orders usually use justifications referring to a single order of worth exclusively, while papers allocated to the uncommon orders usually use justifications referring to multiple different orders of worth. For example, Raghunathan and Sarkar [38] justify their research on bundling of information products exclusively in the market order, stating: "Anecdotal observations in information markets suggest that bundling of information products seems to have emerged as a key design strategy to improve sellers' profitability“ (p. 112). Increasing seller's profitability is apparently considered as a sufficient exclusive justification for research on the topic. On the other hand, Choi, Jiang, Xiao and Kim [14] justify their research on embarrassing exposures in online social networks not only in the fame order (by highlighting negative consequences for the affected individual, as described above) but also in the market order by claiming that such incidents "jeopardize the value of online social networking websites" (p. 675) and "lead to tremendous financial loss to the site" (p. 676). One possible explanation for this difference between papers allocated to the common orders of worth and papers allocated to the uncommon orders of worth is that justifications based exclusively on a single uncommon order of worth might often not be considered sufficient and are hence, supported by justifications based on common orders of worth to strengthen the persuasiveness of the overall justification. Justifications based exclusively on a single common order of worth, in turn, might sometimes neglect additional appropriate justifications in other orders of worth as the justification based on the common order of worth is perceived sufficient in itself.

Secondly, papers allocated to the common orders of worth rather use extant literature to support the overall justification of research than papers allocated to the uncommon orders of worth. Justification of research based on extant literature is usually achieved by answering calls for research or by reviewing extant literature to identify and construct research opportunities and contributions [29]. These literaturebased justifications are often used in combination with justifications based on "real-world" practical considerations (the latter are grounded in the orders of worth). One possible explanation for this difference is the lesser availability of extant literature for research topics justified through uncommon orders of worth. Papers allocated to the common orders of worth in contrast, can often build on extensive literature bases that provide calls for research or can be extensively reviewed and critiqued. As these opportunities are less available for research topics justified through uncommon orders of worth, justifications based on practical considerations in their corresponding orders of worth require even more cogency. 


\section{Discussion}

We assessed how the legitimacy of research is justified by authors in the IS field (at the most influential level). We make three important contributions: (1) we provide a breakdown of the justifications used in IS research - the fundamental reasons why the IS research was done (according to the text), (2) we provide exemplary questions for future research grounded in rarely considered value systems, and (3) we suggest stimuli for the academic community that can foster a broader consideration of varying value systems.

(1) Breakdown of justifications used in IS research: One of the most important and fundamental questions of every discipline is what the ultimate purposes of research are [15] and how potential contributions in that regard can be constructed and justified [29]. We found that IS researcher (at the most influential level) is mostly justified in an economic sense. The vast majority of research papers were justified by either the market order or industrial order. The civic order was the next most dominant order, after the rather economic-based industrial order and market order. The domestic order, inspiration order, fame order and green order were rarely the root for the justifications of research. However, it should be noted that the 2016 special issue "ICT and Societal Challenges" of MIS Quarterly had an impact on the number of occurrences of the civic order which exaggerates this order of worth. Still, the distribution of papers across the market order, industrial order, and civic order (in descending succession) was in fact evident across both journals individually. Hence, our assessment is that the IS field (at the most influential level) is not very diverse in regard to its justifications and relevance interpretations.

Sparse consideration of topics related to other orders of worth (inspiration order, fame order, domestic order) is apparent. For instance, art and creativity (inspiration order) are often not considered as an end in itself but as an instrumental supporter of economic outcomes (e.g., in crowdsourcing). However, research in other disciplines has long shown interest in creativity as an end in itself [e.g., 3]. While IS research already makes important contributions, we believe that the contributions of this field can be further increased through a broader perspective of what constitutes relevant contributions. We think that diversity is a strength of the IS field [cf. 39], not only from the perspective of topics and methods, but also from the perspective of varying justifications and purposes. A broad consideration of relevant research purposes promises to further establish the legitimacy of the IS field as an academic discipline [cf. 18].
Sparse consideration of topics justified in uncommon orders of worth indicates gaps in our current knowledge base. Many potentially important topics are likely neglected in IS research (at least at the most influential level). This issue is likely reinforced by a feedback loop caused by the lack of extant literature on these topics. Considering the emphasis on and practice of cumulative research in the IS field [9], extant literature and its underlying orders of worth can strongly influence the orders of worth to which future researchers subscribe to and consequently the questions they ask. Researchers frequently react to calls for research or construct research opportunities based on extant literature [29]. If research topics that are justified within certain orders of worth are only sparsely existent in extant literature, future researchers more easily overlook these topics (and involuntary reinforcing the feedback loop by not producing related literature for future researchers). Moreover, researchers that do not necessarily overlook these topics might still actively choose topics that are justified within common orders of worth as these usually provide more extensive extant literature to identify and create opportunities and justifications for research endeavors. The lack of extant literature on topics justified in uncommon orders of worth makes it difficult to systematically assess the current knowledge base and identify research directions through common means such as literature reviews.

(2) Exemplary questions for future research: Regarding such rarely considered value systems, we provide some exemplary suggestions for future research. First, research could be concerned with the role of IS for purposes within the domestic order. For example, against recent worries of dividing societies, research might ask the question of how Information Systems can foster mutual trust in a society. More precisely, the question how Information Systems can foster dialogue and understanding between individuals with distinct political views holds substantial value in the domestic order (contrasting "filter bubbles" and mutual distrust). Additionally, potential means to use Information Systems to preserve societal tradition and heritage could have value for many people in the domestic order. Within the inspiration order, future research might engage in questions regarding the role of Information Systems for creativity. For instance, how can Information Systems support the creation and expression of art? This question holds great value for artists in various fields (e.g., music, poetry, art, lyric). Regarding the fame order, research might be concerned with the question how Information Systems can foster attention, recognition or popularity of individuals or groups. Regarding the green order, we believe that IS research has made the right steps in that more and 
more research is concerned with environmental impacts of IS. Comprehensive research agendas have recently been published to guide future research in the green order [e.g., 21]. Consequently, we encourage researchers to continue this road and assume that in the future, the green order will be increasingly represented in IS research.

(3) Stimuli for the academic community: With our analysis, we do not intend to criticize current and past research efforts that are primarily driven by economic factors and application within the economy. Instead, we hope to stimulate more debate and greater consideration of different topics that are relevant from various perspectives. The IS field has potential to make important contributions to a variety of topics and problems outside of economic orders of worth. In the following, we suggest several potential stimuli for the field. These are addressed at the IS-community as a whole, comprising all roles (e.g., authors, reviewers, editors).

First, we believe that special issues (such as the above-mentioned special issue "ICT and Societal Challenges" in MIS Quarterly) offer a great opportunity to engage with value systems that are otherwise underrepresented. We encourage editors and guest editors to use special issues for orders of worth that are rarely considered, rather than only for value systems that would receive attention in regular issues, nonetheless. While we see the value of joint publications of "regular" topics in special issues, we want to emphasize the even greater benefits provided by special issues for research that is legitimized and justified through rarely considered value systems.

We encourage authors to reflect on all possible implications of their research, beyond their main justification in its corresponding value system. The novel type of analysis in this paper provides a means for such reflections on potential implications. Even studies justified within a specific order of worth might yield implications for phenomena in other orders of worth. The framework can also be used in the very early stages of research to identify relevant topics through a broader perspective, by reflecting and considering all possible relevant topics and problems. As such, the paper contributes to IS research in the same way that we train our students: being "critically reflective" of what we do and using higher-level judgement and assessment to choose our research topics rather than blindly following existing blueprints.

We encourage editors and reviewers to carefully evaluate the adequacy of justifications and legitimacy when evaluating submitted papers. It has often been argued that a published manuscript is a product of a negotiation between editors, reviewers and authors [e.g., 7]. Thus, editors and reviewers have a substantial influence on the development of an article and its underlying justification. Some editors and reviewers might dismiss papers that are justified in uncommon value systems or at least induce a shift towards a justification in another value system. Authors will often act on such revision requirements unopposed in order to "please referees and editors" [7 p. 199]. As a result, however, important and relevant contributions (within a variety of value systems) might be lost in the review process in favor of contributions in more established and common value systems. In line with prominent endorsements of diversity in IS, we believe that the IS field should be open towards diverse research practices and prevent and orthodoxy which precludes the use or publishing of other research [33]. Hence, we encourage editors and reviewers to be open towards a diverse set of value systems in which justifications of research can be grounded in. We believe that the judgement of justifications and consequently legitimacy of research should primarily be based on the adequacy and argumentation of the justification within the given value system, less on the specific value system itself. Of course, outlet-specific or issue-specific exceptions to that (e.g., by focusing on topics within a specific value system for a special issues) are still appropriate. However, such restrictions should be communicated clearly in call for papers or mission statements. Without such upfront restrictions however, we believe that a submission should not be dismissed, based only on the given value system (in which the justification might be perfectly argued and adequate).

Some specificities and limitations of our study need to be considered. The identification and assessment of the justifications in the individual studies were hardly based on explicit statements within the papers. That is, authors hardly explicitly articulate the type of value that they see in their research. We therefore assessed the justifications of the papers indirectly, by identifying justifying statements based on the orders of worth framework [11]. Furthermore, our data set does not cover the entire range of outlets in IS. Our analysis is based on an assessment of the two leading journals of the IS field. These however do not necessarily constitute an average representation of thematic coverage and distribution of justifications across various value systems in IS research. Instead, they might focus primarily on economic value systems and IS researchers, which are often hosted at business schools, might specifically value such journals (and their focal value systems) for career considerations. Papers that are based on rarely considered (according to our analysis) orders of worth might be represented more frequently in other journals. Therefore, using other journals with other scopes and different thematic 
foci for the analysis could lead to a different assessment. We recognize that no subset of outlets can fully represent the IS field. However, the two chosen journals are of generalist nature and the most influential outlets in IS. Hence, we believe they provide the best sample for such assessments. The results should still not be generalized to all IS outlets or the field as such, unquestioned.

\section{Conclusion}

This study analyzed the prevailing justifications in the IS research literature. We assessed, in particular, how authors justify their research. We provide a breakdown of the justifications used in IS research and assess how IS research justifies its legitimacy. We used the orders of worth framework [11] to map the justifications of individual research papers. We quantitatively analyzed the occurrence of orders of worth in the literature. Our findings show that IS research is predominantly justified and legitimized through value in the market order and industrial order. We suggest that researchers should consider a diverse set of relevant research purposes to enhance their contributions, to extend our knowledge base and to further establish the legitimacy of IS research in accordance with other orders of worth.

\section{References}

[1] Agarwal, A., Mukhopadhyay, T., "The Impact of Competing Ads on Click Performance in Sponsored Search", Information Systems Research 27(3), 2016, pp. 538-557

[2] Agarwal, R., Lucas, H., "The Information Systems Identity Crisis: Focusing on High-Visibility and High-Impact Research“, MIS Quarterly 29(3), 2005, pp. 381-398

[3] Amabile, T.M., "The Social Psychology of Creativity: A Componential Conceptualization", Journal of Personality and Social Psychology 45(2), 1983, pp. 357-377

[4] Andrade, A.D., Doolin, B., "Information and Communication Technology and the Social Inclusion of Refugees“, MIS Quarterly 40(2), 2016, pp. 405-416

[5] Bapna, R., Gupta, A., Ray, G., Singh, S., "Research Note-IT Outsourcing and the Impact of Advisors on Clients and Vendors“, Information Systems Research 27(3), 2016, pp. 636-647

[6] Bauer, J., Franke, N., Tuertscher, P., "Intellectual Property Norms in Online Communities: How UserOrganized Intellectual Property Regulation Supports Innovation“, Information Systems Research 27(4), 2016, pp. 724-750

[7] Bedeian, A.G., "Peer Review and the Social Construction of Knowledge in the Management Discipline“, Academy of Management Learning \& Education 3(2), 2004, pp. 198-216

[8] Benbasat, I., Weber, R., "Research CommentaryRethinking Diversity in Information Systems Research“, Information Systems Research 7(4), 1996, pp. 389-399
[9] Benbasat, I., Zmud, R.W., "Empirical Research in Information Systems: the Practice of Relevance", MIS Quarterly 23(1), 1999, pp. 3-16

[10] Benbasat, I., Zmud, R.W., "The Identity Crisis within the IS Discipline: Defining and Communicating the Discipline's Core Properties“, MIS Quarterly 27(2), 2003, pp. 183-194

[11] Boltanski, L., Thévenot, L., On Justification: Economies of Worth. Princeton University Press, Princeton, 2006

[12] Carter, M., Grover, V., "Me, My Self, and I(T): Conceptualizing Information Technology Identity and its Implications“, MIS Quarterly 39(4), 2015, pp. 931-957

[13] Chen, Y.J., Huang, K.W., "Pricing Data Services: Pricing by Minutes, by Gigs, or by Megabytes per Second?", Information Systems Research 27(3), 2016, pp. 596-617

[14] Choi, B.C., Jiang, Z., Xiao, B., Kim, S.S., "Embarrassing Exposures in Online Social Networks: An Integrated Perspective of Privacy Invasion and Relationship Bonding", Information Systems Research 26(4), 2015, pp. 675-694

[15] Constantinides, P., Chiasson, M.W., Introna, L.D., "The Ends of Information Systems Research: a Pragmatic Framework", MIS Quarterly 36(1), 2012, pp. 1-21

[16] Davenport, T., Markus, M., "Rigor vs. Relevance Revisited: Response to Benbasat and Zmud“, MIS Quarterly 23(1), 1999, pp. 19-23

[17] Dequech, D., "Logics of Justification and Logics of Action ", Journal of Economic Issues 42(2), 2008, pp. 527535

[18] DeSanctis, G., "The Social Life of Information Systems Research: A Response to Benbasat and Zmud's Call for Returning to the IT Artifact", Journal of the Association for Information Systems 4(7), 2003, pp. 360-376

[19] DiMaggio, P., "Culture and Cognition“, Annual Review of Sociology 23(1), 1997, pp. 263-287

[20] Dowling, J., Pfeffer, J., "Organizational Legitimacy: Social Values and Organizational Behavior", Pacific Sociological Review 18(1), 1975, pp. 122-136

[21] Elliot, S., Webster, J., "Special Issue on Empirical Research on Information Systems Addressing the Challenges of Environmental Sustainability: An Imperative for Urgent Action“, Information Systems Journal 27(4), 2017, pp. 367378

[22] Han, W., Ada, S., Sharman, R., Rao, H.R., "Campus Emergency Notification Systems: An Examination of Factors Affecting Compliance with Alerts“, MIS Quarterly 39(4), 2015, pp. 909-929

[23] Hong, W., Chan, F.K.Y., Thong, J.Y.L., Chasalow, L.C., Dhillon, G., "A Framework and Guidelines for Context-Specific Theorizing in Information Systems Research“, Information Systems Research 25(1), 2014, pp. 111-136

[24] Johnson, S.L., Safadi, H., Faraj, S., "The Emergence of Online Community Leadership“, Information Systems Research 26(1), 2015, pp. 165-187

[25] Ketter, W., Peters, M., Collins, J., Gupta, A., "A Multiagent Competitive Gaming Platform to Address Societal Challenges“, MIS Quarterly 40(2), 2016, pp. 447460

[26] King, J., Lyytinen, K., Information Systems: The State of the Field. John Wiley \& Sons, Chichester, UK, 2006 
[27] Latour, B., Woolgar, S., Laboratory Life: The Construction of Scientific Facts. Sage, Beverly Hills, CA: , 1979

[28] Leong, C.M.L., Pan, S.L., Newell, S., Cui, L., "The Emergence of Self-Organizing E-Commerce Ecosystems in Remote Villages of China: A Tale of Digital Empowerment for Rural Development", MIS Quarterly 40(2), 2016, pp. 475-484

[29] Locke, K., Golden-Biddle, K., "Constructing Opportunities for Contribution: Structuring Intertextual Coherence and "Problematizing" in Organizational Studies", Academy of Management Journal 40(5), 1997, pp. 10231062

[30] Lyytinen, K., King, J.L., "Nothing At The Center?: Academic Legitimacy in the Information Systems Field", Journal of the Association for Information Systems 5(6), 2004, pp. 220-246

[31] Miranda, S.M., Young, A., Yetgin, E., "Are Social Media Emancipatory or Hegemonic? Societal Effects of Mass Media Digitization“, MIS Quarterly 40(2), 2016, pp. 303-329

[32] Nicolai, A., Seidl, D., "That's Relevant! Different Forms of Practical Relevance in Management Science“, Organization Studies 31(9-10), 2010, pp. 1257-1285

[33] Orlikowski, W.J., Baroudi, J.J., "Studying Information Technology in Organizations: Research Approaches and Assumptions“, Information Systems Research 2(1), 1991, pp. $1-28$

[34] Orlikowski, W.J., Iacono, C.S., "Research Commentary: Desperately Seeking the "IT" in IT Research-A Call to Theorizing the IT Artifact", Information Systems Research 12(2), 2001, pp. 121-134

[35] Parsons, T., Structure and Process in Modern Societies. Free Press, New York, 1960

[36] Patriotta, G., Gond, J.-P., Schultz, F., "Maintaining Legitimacy: Controversies, Orders of Worth, and Public Justifications“, Journal of Management Studies 48(8), 2011, pp. 1804-1836

[37] Prawesh, S., Padmanabhan, B., "The "Most Popular News" Recommender: Count Amplification and Manipulation Resistance", Information Systems Research 25(3), 2014, pp. 569-589

[38] Raghunathan, S., Sarkar, S., "Competitive Bundling in Information Markets: A Seller-Side Analysis“, MIS Quarterly 40(1), 2016, pp. 111-131

[39] Robey, D., "Research Commentary-Diversity in Information Systems Research: Threat, Promise, and Responsibility“, Information Systems Research 7(4), 1996, pp. $400-408$

[40] Robey, D., Markus, M.L., "Beyond Rigor and Relevance: Producing Consumable Research About Information Systems“, Information Resources Management Journal 11(1), 1998, pp. 7-15

[41] Rosemann, M., Vessey, I., "Toward Improving the Relevance of Information Systems Research to Practice: The Role of Applicability Checks“, MIS Quarterly 32(1), 2008, pp. 1-22

[42] Sarker, S., Xiao, X., Beaulieu, T., Lee, A.S., "Learning from First-Generation Qualitative Approaches in the IS Discipline: An Evolutionary View and Some Implications for Authors and Evaluators (PART 1/2)“, Journal of the
Association for Information Systems 19(8), 2018, pp. 752774

[43] Shen, W., Hu, Y.J., Ulmer, J.R., "Competing for Attention: An Empirical Study of Online Reviewers' Strategic Behavior“, MIS Quarterly 39(3), 2015, pp. 683-696 [44] Subramanian, H., Overby, E., "Electronic Commerce, Spatial Arbitrage, and Market Efficiency“, Information Systems Research 28(1), 2016, pp. 97-116

[45] Thévenot, L., Moody, M., Lafaye, C.: Forms of Valuing Nature: Arguments and Modes of Justification in French and American Environmental Disputes. In: Thévenot, L., Lamont, M. (eds.) Rethinking Comparative Cultural Sociology: Repertoires of Evaluation in France and the United States, pp. 229-272. Cambridge University Press, Cambridge, 2000

[46] Thévenot, L.: Conventions of Co-Ordination and the Framing of Uncertainty. In: Fullbrook, E. (ed.) Intersubjectivity in Economics, pp. 181-197. Routledge, London, 2002

[47] Thornton, P.H., Ocasio, W., "Institutional Logics and the Historical Contingency of Power in Organizations: Executive Succession in the Higher Education Publishing Industry“, American journal of Sociology 105(3), 1999, pp. 801-843

[48] Thornton, P.H., Ocasio, W., Lounsbury, M., The Institutional Logics Perspective: A new Approach to Culture, Structure, and Process. Oxford University Press, Oxford, UK, 2012

[49] Tian, F., Xu, S.X., "How Do Enterprise Resource Planning Systems Affect Firm Risk? Post-Implementation Impact", MIS Quarterly 39(1), 2015, pp. 39-60

[50] Venters, W., Oborn, E., Barrett, M., "A Trichordal Temporal Approach to Digital Coordination: The Sociomaterial Mangling of the CERN Grid“, MIS Quarterly 38(927-949), 2014,

[51] Vom Brocke, J., Watson, R.T., Dwyer, C., Elliot, S., Melville, N., "Green Information Systems: Directives for the IS Discipline", Communications of the Association for Information Systems 33(30), 2013, pp. 509-520

[52] Wu, S.P.J., Straub, D.W., Liang, T.P., "How Information Technology Governance Mechanisms and Strategic Alignment Influence Organizational Performance: Insights from a Matched Survey of Business and IT Managers“, MIS Quarterly 39(2), 2015, pp. 497-518

[53] Yeow, A., Huat Goh, K., "Work Harder or Work Smarter? Information Technology and Resource Allocation in Healthcare Processes“, MIS Quarterly 39(4), 2015, pp. 763-786 